\title{
MORIR DE HAMBRE EN LAS CÁRCELES DE FRANCO (1939-1945)
}

\section{DIE OF HANGER IN THE PRISONS OF FRANCO (1939-1945)}

\author{
Domingo Rodríguez Teijeiro \\ Universidad de Vigo
}

Entregado el 1-6-2014 y aceptado el 11-3-2015.

\begin{abstract}
Resumen: El objetivo del presente trabajo es realizar un acercamiento a lo que fueron las condiciones de vida en las prisiones franquistas de posguerra, centrándonos en las consecuencias que se derivan de la insuficiente alimentación que recibían los presos. Hacemos un breve recorrido por la memoria de los presos, que nos han dejado constantes referencias a su escasez y nulo aporte alimenticio. Estudiamos las normas remitidas a todos los centros de reclusión desde la Inspección Central de Sanidad de la Dirección General de Prisiones en las que se establecían directrices a seguir en lo tocante a la alimentación, que muestran una total desconexión de la realidad. Contrastamos esas normas con los informes elaborados por los médicos, en concreto, el amplio informe remitido por el responsable de la Prisión Provincial de Ourense que llama la atención sobre las consecuencias de la subalimentación a que se ven sometidos los reclusos. Finalmente, en las conclusiones, avanzamos una cifra del número de fallecidos en las prisiones durante la posguerra, a partir de los escasos datos disponibles.
\end{abstract}

Palabras clave: Franquismo, represión, cárcel, posguerra, hambre, desnutrición.

\footnotetext{
${ }^{1}$ El presente trabajo se enmarca en el proyecto de investigación HAR 2012-38659. La represión franquista sobre las mujeres. Galicia, 1936-1953. Dirigido por el profesor Jesús de Juana López.
} 


\begin{abstract}
The objective of this paper is an approach to what were the conditions of life in postwar Francoist prisons, focusing on the consequences of poor nutrition that prisoners received. We make a brief tour of the memory of the prisoners who have left us constant references about the poor food supply. We study the rules sent to all prisons from the Dirección General de prisiones in which they established guidelines to follow in relation to the feeding of prisiones, showing a total disconnection from reality. We contrast these standards with the reports made by the doctors, in particular, the comprehensive report submitted by the doctor responsable of the Prisión Provincial de Ourense that call attention about the consequences of malnutrition. Finally, in the conclusions, we advance a figure on the number of deaths in prisons during the postwar, based on the limited data available .
\end{abstract}

Key words: Francoism, repression, prison, post-civil war, famine, malnutrition. 
Con el final de la contienda un sector importante de la población - generalmente identificado con los vencidos, pero no solo ellos - se verá obligada a hacer frente a una situación de penuria extrema. La escasez generalizada de alimentos, que según el gobierno responde a «cierta tendencia al acaparamiento de algunas mercancías, movida por el agio y fomentada por falsas noticias», obliga a instaurar con carácter general la cartilla familiar de racionamiento (en realidad dos cartillas: una para carnes y otra para los demás alimentos) en mayo de $1939^{2}$. En julio se establecían las raciones tipo, diarias y de carácter individual, «correspondientes al hombre adulto» (para las mujeres y los mayores de 60 años la ración sería un $80 \%$ de esta y para los niños hasta 14 años un 60\%), que quedaban del siguiente modo: Pan (400 grs.), Patatas (250 grs.), Legumbres secas (garbanzos, judías, lentejas, arroz) (100 grs.), Aceite (50 grs.), Café (10 grs.), Azúcar (30 grs.), Carne (125 grs.), Tocino (25 grs.), Bacalao (75 grs.), Pescado fresco (200 grs.).

En la orden que establece esa «ración tipo» se señalaba que respondía únicamente a la intención de regular la distribución de cada uno de los artículos incluidos en ella y que, en ningún caso, debería entenderse como la ración que, efectivamente, hay que suministrar diariamente. En la misma fecha se procede a regular el comercio interprovincial de alimentos, que no podrán ser transportados sin autorización de la Delegación Provincial de Abastos, y entre los que figuran: patatas, arroz, garbanzos, judías, lentejas, azúcar, café, aceite, piensos, ganado vacuno, ganado lanar, ganado de cerda, carne congelada, tocino, bacalao, huevos y leche condensada ${ }^{3}$, es decir, todos aquellos que se encuentran racionados.

Con estas normas se daba inicio a un sistema que permanecería en vigor hasta el 16 de mayo de 1952, proporcionando a los españoles un suministro tan escaso y desequilibrado que no aportaba los nutrientes necesarios para garantizar la supervivencia a una persona normal: la década de los cuarenta, y muy especialmente su primera mitad, han pasado a la memoria popular como «los años del hambre», caracterizados por la realidad cotidiana del racionamiento insuficiente y los productos de estraperlo a un precio desorbitado.

2 Orden del Ministerio de Industria y Comercio de 14 de mayo de 1939, B.O.E. de 17 de mayo.

3 Ordenes del Ministerio de Industria y Comercio de 28 de junio de 1939, B.O.E. de 1 de julio. 
En las prisiones estas carencias alimentarias serán, como se puede suponer, mucho más acusadas. En el presente trabajo abordamos las consecuencias que se derivan de una falta de alimentación adecuada, para ello, en primer lugar y de manera breve, nos acercaremos a la alimentación tal y como ha quedado plasmada en la memoria de los presos, que nos han dejado constantes referencias a su escasez y nulo aporte alimenticio. Una preocupación que era compartida también por los responsables de las prisiones, si bien, lo habitual en este último caso es que hiciesen un lucrativo negocio desviando al mercado negro buena parte de los productos que entraban en las cárceles y que nunca llegaban a la cocina, incrementando así la subalimentación de los presos. Una situación especialmente grave en los primeros años de la década de los cuarenta, propiciada por el elevado número de reclusos, y que se traduce en la generalizada depauperación de los presos y en la aparición de estados carenciales que, en más de una ocasión, tendrán como consecuencia el fallecimiento por inanición. Pero la falta de alimentación, que disminuye las defensas del organismo, también convierte a la población reclusa en el terreno idóneo para el desarrollo de otro tipo de enfermedades que incrementarán los índices de mortalidad.

Más allá de la memoria, la fuente básica de este trabajo está constituida por las normas remitidas a todos los centros de reclusión desde la Inspección Central de Sanidad de la Dirección General de Prisiones estableciendo las directrices que deben regir la alimentación de los presos y por un amplio informe que el médico de la Prisión Provincial de Ourense envía a ese mismo centro en el que llama la atención sobre las consecuencias de la subalimentación entre los reclusos de la prisión que tiene a su cargo. Del análisis de ambos documentos se desprende la total desconexión de la realidad en que viven los responsables centrales del sistema penitenciario franquista, que proponen unas dietas tipo compuestas por alimentos que hace ya mucho tiempo que no entran en las prisiones. A pesar de lo anterior, como veremos, la alimentación y las medidas que se adoptan para su gestión no dejarán de constituir un importante elemento propagandístico en las páginas del semanario $R e$ dención.

Una cuestión que conviene tener en cuenta es que aunque serán mayoritarios los presos políticos, en las prisiones de posguerra existirán también presos por delitos comunes. En el periodo que aquí nos ocupa representan un porcentaje reducido de la población reclusa, aunque en 1945 ya 
alcanzan el $32,36 \%$ del total de reclusos ${ }^{4}$, que se verán sometidos a las mismas privaciones - sino mayores - que los políticos.

\section{La alimentación: preocupación básica de los presos}

A medida que se desarrolla la Guerra Civil y los sublevados ocupan nuevos territorios el número de reclusos en las cárceles franquistas se irá incrementando de manera progresiva. Si bien carecemos de fuentes que nos permitan acercarnos a su número real durante los años de guerra diferentes autores apuntan algunas cifras que permiten observar esa progresión, y así de los 64.719 que habría en septiembre de 1937 se pasará a los 100.242 en abril de $1939^{5}$, en el momento en que finaliza. Durante los primeros meses de la posguerra, a medida que se cierran los campos de concentración para prisioneros de guerra, la población penitenciaria crecerá de manera exponencial, alcanzándose la cifra de 270.719 presos a comienzos de $1940^{6}$. La sobreocupación será una característica de las prisiones que quedan en la retaguardia de los sublevados desde los primeros momentos — tal es el caso de $\mathrm{Galicia}^{7}$-, que deben acomodar en su interior a un número de internos tres, cuatro o cinco veces superior a lo que se consideraba su capacidad normal, por lo que se hace necesario recurrir a la creación de nuevas prisiones «habilitadas» empleando para ello monasterios, fábricas, casas particulares o cualquier espacio con capacidad suficiente y unas mínimas garantías para su vigilancia y control.

Si esas condiciones de sobreocupación, además de los problemas estructurales que presentan los edificios habilitados como prisiones, impiden dar a los reclusos un alojamiento mínimamente digno, en lo que hace

${ }^{4}$ Un análisis pormenorizado de las cifras oficiales de presos en la década de los cuarenta puede verse en Jesús de Juana y Domingo Rodríguez Teijeiro, «Presos en la España de posguerra (1939-1950)», en Juan Aviles Farré, Historia, política y cultura. Homenaje a Javier Tusell, UNED, Madrid, 2009, pp. 187-224.

${ }^{5}$ José Ignacio Berdugo, Josefina Cuesta, M. a Dolores de la Calle y Mónica Lanero, «El Ministerio de Justicia en la España "Nacional"», en VV.AA., Justicia en Guerra. Jornadas sobre la Administración de Justicia durante la Guerra Civil Española. Instituciones y fuentes documentales, Ministerio de Cultura, Madrid, 1990, p. 281.

6 Vid. Jesús de Juana y Domingo Rodríguez, «Presos...» op. cit.

7 Sobre las prisiones gallegas véase Domingo Rodríguez Teijeiro, Presos e prisións na Galicia de Guerra e Posguerra, Galaxia, Vigo, 2010. 
referencia a su alimentación las autoridades penitenciarias - aunque quisieran, que no siempre era así- no estaban en condiciones de aportar los medios precisos para atender a sus necesidades más básicas ${ }^{8}$. Las dificultades se dejaran sentir ya desde agosto de 1936 y no harán sino empeorar durante los tres años siguientes, pero en la inmediata posguerra serán especialmente graves y dramáticas.

La escasez de alimento, el hambre, ocupa en la memoria de los presos un lugar prominente y se convierte en uno de los elementos más empleados a la hora de definir lo que fueron las condiciones de vida en aquellos espacios de reclusión. Todos los testimonios dedican un amplio espacio a describir la «dieta de hambre» que se veían obligados a seguir, una dieta que constituye un sufrimiento añadido a la pérdida de libertad, una auténtica pena accesoria, no tipificada, pero que se suma a la impuesta por el tribunal y que, sobre todo en aquellos casos en que los reclusos no recibían ningún tipo de ayuda del exterior, equivale a una sentencia de muerte que se ejecuta en un plazo de tiempo más largo.

En ocasiones la deficiente infraestructura con que cuentan los centros de reclusión, que carecen hasta de servicio de cocina, lleva a que sus responsables entreguen a los presos la cantidad que les corresponde en concepto de alimentación para que sean ellos mismos quienes realicen las compras en el exterior. Así ocurre, por ejemplo, en la prisión de Partido de Santiago de Compostela donde, en el verano de 1936, los reclusos reci-

8 Es ya relativamente abundante la bibliografía sobre los espacios de reclusión franquistas. Para acercase a las prisiones y las condiciones de vida en su interior pueden ser útiles, entre muchos otros: Ascensión Badiola, Cárceles y campos de concentración en Bizkaia (1937-1940), Txertoa, Donostia, 2011; Encarnación Barranquero (et. al.), Mujer, cárcel y franquismo. La prisión provincial de Málaga (1937-1945), Junta de Andalucía, Málaga, 1994; Gutmaro Gómez Bravo, El exilio interior. Cárcel y represión en la España de postguerra. 1939-1950, Taurus, Madrid, 2009; Fernanado Hernández Holgado, La prisión Militante. Las cárceles franquistas de mujeres de Barcelona y Madrid, Tesis Doctoral, disponible en http://eprints.ucm.es/13798/; Encarnación Barranquero Texeira, Mujeres en la guerra civil y el franquismo: violencia, silencio y memoria de los tiempos difíciles, Diputación Provincial, Málaga, 2010; Ricard Vinyes Ribas, Irredentas. Las presas políticas y sus hijos en las cárceles franquistas, Temas de Hoy, Madrid, 2002; Fernando Cardero Azofra, El penal de Valdenoceda, Cálamo, Palencia, 2011; una visión de larga duración se puede encontrar en Pedro Oliver Olmo (coord.), El siglo de los castigos. Prisión y formas carcelarias en la España del siglo XX, Anthropos, Barcelona, 2013; Pedro Oliver Olmo y Jesús Carlos Urda Lozano, La prisión y las instituciones punitivas en la investigación histórica, Universidad de Castilla-La Mancha, Cuenca, 2014. 
ben diariamente 1,50 ptas. con las que tienen que atender al desayuno, comida y cena; una cantidad insuficiente que no habría permitido la supervivencia de no ser por los alimentos enviados por familiares o amigos y, en el caso de quienes no contaban con esta ayuda, sólo por la generosidad de una vecina de la ciudad que les confeccionaba las tres comidas por 1 peseta diaria ${ }^{9}$.

Generosidad o negocio, en las localidades donde se ubican los centros de reclusión proliferan establecimientos o incluso personas particulares que, por un importe semejante a la asignación diaria estipulada para la alimentación de los presos, se comprometen a hacerles llegar, al menos, una comida diaria. Tenemos constancia de que así ocurría, ya en la posguerra, en la prisión Central de Celanova donde los familiares que acudían de visita dejaban dinero a vecinos de la villa que suministraban al preso una comida diaria hasta que se agotaba la asignación, algo que también era frecuente en Tarragona con los presos recluidos en Pilatos ${ }^{10}$.

En la prisión Central de Figueirido, en Pontevedra, creada 1938 para acoger penados como consecuencia de la caída del Frente Norte y con una población reclusa que rondará el millar de presos, la comida no será mala en los primeros momentos: un «sucedáneo» de café con leche por las mañanas y garbanzos con fideos o judías blancas - o bien patatas y judías de color con algo de tocino- en el almuerzo y la cena. Los presos asturianos dejarán constancia de la importante mejora del rancho en comparación con lo que recibían en la Cárcel de El Coto, en Gijón, pero a medida que pasa el tiempo irá deteriorándose. La base fundamental de la alimentación de los reclusos estará constituida, como en muchas otras prisiones, por aquellos artículos que recibían en los paquetes enviados por la familia y, cuando disponían de recursos, lo que se podía comprar en el economato ${ }^{11}$.

Con el final de la contienda, la escasez y la insuficiencia alimentaria se convierten en la norma en todos los centros de reclusión. Sirvan, a

\footnotetext{
9 Isabel Ríos, Testimonio de la Guerra Civil, Ediciós do Castro, Sada-A Coruña, 1986, p. 82

10 Vid. Concha López Sarasúa, Celanova 42, Cálamo, Alicante, 1993 y Josep Subirats Piñana, Pilatos 1939-1941. Prisión de Tarragona, Pablo Iglesias, Madrid, 1993, p. 37.

11 Marcelino Laruelo Roa, La libertad es un bien muy preciado. Consejos de Guerra, Edición en CD-ROM, s.d., s.p.
} 
modo de ejemplo, los casos de la prisión Provincial de Cádiz donde, en 1939, se empleaba agua de algarrobo para sustituir al café del desayuno y el rancho del mediodía era un cazo de acelgas con algo de «pescado»: las espinas ${ }^{12}$; las de Cartagena, en 1940, la base de la alimentación era también un caldo hecho con las vainas de algunas legumbres y en el que, con suerte, se podían encontrar algunos rábanos; o la prisión de Alcalá de Henares, donde el café del desayuno no consistía sino en agua teñida y el rancho era un cazo de arroz con calabaza o col, junto con 50 grs. de pan para todo el día ${ }^{13}$. Podríamos hacer más larga la anterior lista y continuar aportando testimonios, todos ellos coinciden en señalar las similitudes que existen entre los distintos centros de reclusión en lo tocante a los productos empleados para la alimentación de los presos. Realmente, bastaría con un único libro de memorias para ejemplificar este aspecto de las condiciones de vida en todas las cárceles de posguerra ya que en todos los existentes se dibuja un panorama tan similar de penuria extrema que podría pensarse que los testigos hablan del mismo centro de reclusión.

Las consecuencias de esa falta de alimentación son fáciles de deducir: depauperación y estados carenciales que, si no tienen como resultado directo el fallecimiento por inanición, sí que convierten a la población reclusa en el terreno idóneo para el desarrollo de otro tipo de enfermedades que incrementarán los índices de mortalidad.

La falta de alimentos hace que los presos se debiliten, enfermen y, en muchos casos, finalmente mueran de pura inanición. En la Prisión de Ocaña, especialmente los que no recibían nada del exterior, se identifican fácilmente porque pierden fuerzas, se les ve caminar como sonámbulos y acaban por ingresar en la enfermería, de la que ya no salen ${ }^{14}$. En estas condiciones, la mortalidad se dispara: según Diego San José, en la Colonia Penitenciaria de San Simón, en 1941, como consecuencia directa del hambre habrían fallecido «en menos de tres meses» trescientos internos ${ }^{15}$;

12 Diógenes Díaz Cabrera, Once cárceles y destierro, el autor, Santa Cruz de Tenerife, 1980 , p. 34.

13 Juan Manuel Molina, Noche sobre España. Siete años en las prisiones de Franco, Libro Mex, México, 1958, p. 106.

14 Testimonio de F. Hernández Girbal, en Rodolfo Serrano y Daniel Serrano, Toda España era una cárcel, Punto de Lectura, Madrid, 2003, p. 50.

15 Diego San José, De cárcel en cárcel, Eds. do Castro, Sada-A Coruña, 1988, p. 209. Aunque todos los testimonios señalan las pésimas condiciones de vida en la isla, sin embargo, no tenemos constancia documental de que esta cifra se ajuste a la 
en la prisión Provincial de A Coruña, durante el invierno de 1940-41, según algunos testimonios todos los días se producen dos, tres y hasta cinco fallecimientos ${ }^{16}$. Aunque no señala la fecha, Moreno Gómez aporta el dato de 144 fallecidos «por hambre» en 16 meses en las tres prisiones creadas en Almendralejo (Badajoz) ${ }^{17}$.

No creemos que el hambre constituya una estrategia diseñada por las autoridades penitenciarias para el exterminio de los reclusos - otra cosa muy diferente es la actitud que muestran los funcionarios de algunas prisiones - , a fin de cuentas por entonces el hambre era algo habitual en las calles de todas las ciudades y pueblos de España, sin embargo sí que cumplirá un papel importante en la función asignada a las prisiones. Aunque esas mismas autoridades reconocen que la situación puede derivar en problemas de orden en el interior de los centros de reclusión, en la mayor parte de los casos la preocupación por la supervivencia inmediata reduce a los presos a la impotencia y aleja cualquier pretensión de resistencia o rebeldía; Carlota O'Neill lo expresa con palabras que no necesitan de mayor comentario:

«El hambre era como una lima en mi organismo, me sentía raspada por ella en arteria, músculos, huesos; la sangre se me hacía blanca en los labios y en las encías; el hambre era como la portera de la muerte; esto me consolaba y, sobre todo, me «entregaba», sin protesta ni rebeldía a mi destino, que podía más que yo» ${ }^{18}$.

\section{El negocio de la alimentación}

Buena parte de la escasez que se vive en las prisiones cabe atribuirla a la especulación que sus responsables realizan con los suministros que reciben y, de manera especial, los destinados a la alimentación de los presos. Un negocio que reporta importantes beneficios a muchos funcionarios de prisiones. Falsificar las cuentas del peculio de los presos y

realidad; sea cierta o no, da idea de cómo era vivida esa situación de precariedad por los reclusos.

16 Testimonio de José Queiruga Allegue, cit. Xerardo Díaz Fernandez, A crueldade inútil, Eds. do Castro, Sada-A Coruña, 1982, p. 118.

17 Francisco Moreno, «La represión...» op. cit., p. 290.

18 Carlota O'Neill, Una mujer... op. cit., p. 158. 
quedarse con parte del dinero que les llegaba a través de giros postales es algo que se repite en diferentes prisiones, como también lo es la elevación del precio en los productos que se venden en el economato, generalmente superior al que tienen en la calle ${ }^{19}$. Sin embargo, el negocio más lucrativo -y que quizá tuvo mayor incidencia en el empeoramiento de las condiciones de vida de los presos - consistía en revender en el mercado negro los artículos que debían destinarse a la confección del rancho. Por poner algún ejemplo, en la prisión de Córdoba, el practicante - que no era funcionario - se llevaba el azúcar destinado a los presos ${ }^{20}$, mientras que en la de Saturrarán las monjas encargadas de la dirección del centro vendían en el exterior los alimentos al tiempo que las reclusas enfermaban de avitaminosis $^{21}$.

En la Central de Astorga los oficiales y el guardián de la prisión, quizá por haber quedado al margen del negocio, acusan al director de que el racionado que se repartía a los reclusos era inferior al coste que se justificaba en las cuentas; y en la Prisión de Yeserías, de Madrid, según la denuncia presentada por un ex-recluso ante el Ministro de Justicia en 1941, la comida que se daba a los presos no valía más de 50 cts. por plaza y día ${ }^{22}$. En algunas prisiones de Toledo, los partes de cocina se falsifican y se hacen constar comidas que no existen, alimentándose los reclusos a base de caldo de nabos y repartiéndose el beneficio los fun-

19 En la prisión de mujeres de Saturrarán, el funcionario que estaba encargado de recoger los giros se quedaba con el dinero en lugar de ingresarlo en la cuenta de las presas, cuando hubo conseguido una cantidad importante desapareció de la prisión, aunque fue muy pronto detenido. Isabel Ríos, Testimonio... op. cit., p. 158. De este tipo de prácticas también se acusará al Administrador de la Prisión Central de Celanova en 1938, vid. Archivo de la Delegación de Defensa de Ourense, (A.D.O), causa 795/38.

20 Testimonio de Sama Naharro, a quien el médico de la prisión le comentaba al respecto: «lo que pasa es que los oficiales se han dividido: los nuevos quieren robar y los viejos también, y no dejan a otros», cit. Francisco Moreno, «La represión...», op. cit., p. 295.

${ }^{21}$ Según se relata en Ángel Suárez (Libro blanco sobre las cárceles franquistas, Ruedo Ibérico, París, 1976, p. 72), ante la situación de la población reclusa en esta prisión las autoridades penitenciarias envían una directora del cuerpo de prisiones y «al llegar encontró a las presas moribundas y los almacenes repletos de judías, patatas y bacalao, listo para sacarlo del establecimiento por la puerta de atrás».

22 Ángela Cenarro, «La institucionalización del universo penitenciario franquista» en Jaume Sobrequés, Carme Molinero y Margarida Sala (coords.), Una inmensa prisión: los campos de concentración y las prisiones durante la Guerra Civil y el Franquismo, Crítica, Barcelona, 2003, pp. 151-152. 
cionarios y proveedores; en la prisión de Talavera de la Reina, los funcionarios venden el aceite y el azúcar a industriales y comerciantes de la ciudad y, aunque acaba por realizarse una investigación, estos no serán sancionados ${ }^{23}$.

Un tipo de actividades que parecen estar tan extendidas que, en ocasiones, eran recogidas en el semanario Redención, donde se informaba de las sanciones impuestas a los funcionarios que eran sorprendidos, como ocurre con el Jefe de la Prisión de Daimiel quien será sancionado con la separación del servicio y baja en el escalafón porque «no inspeccionaba el suministro y faltaba parte de la carne destinada a los reclusos». En este caso se da cuenta de los mecanismos de tan lucrativo negocio: haciendo figurar cantidades como invertidas sin que hubiera concordancia en los precios ni en las cantidades de los productos suministrados, o bien vender directamente en el mercado negro - a través de un familiar, que realizaba diferentes servicios en la prisión si tener la categoría requerida ni formar parte del Cuerpo de Prisiones - la carne destinada a los reclusos. Tanto la sanción, como la publicidad dada a este caso constituyen una excepción ya que, lo habitual, como ocurre con otro tipo de prácticas - las denuncias por malos tratos, por ejemplo- era que el expediente abierto terminara por ser sobreseído por falta de pruebas $^{24}$.

\section{Las consecuencias del hambre: estados carenciales y avitaminosis}

Se ha definido la nutrición como un conjunto de procesos a través de los cuales los seres vivos utilizan, transforman e incorporan a sus propias estructuras aquellas substancias que toman del mundo exterior para obtener energía, construir y reparar su estructura orgánica y regular sus procesos metabólicos. Esas substancias, los nutrientes, se obtienen fundamentalmente a través de los alimentos, y están constituidos por los carbohidratos, proteínas, lípidos, vitaminas, minerales y agua. Para vivir, el

23 José Manuel Sabín, «Toledo y la guerra» en Manuel Ortiz Heras, La Guerra Civil en Castilla-La Mancha. De El Alcázar a Los Llanos, Celeste, Madrid, 2000, p.160.

${ }^{24}$ Redención. Órgano del Patronato Para la Redención de las Penas por el Trabajo, 1 de junio de 1940,p. 1. Una acusación similar dará lugar a la apertura de una voluminosa causa militar al Administrador de la Prisión Central de Celanova que finalmente acaba en sobreseimiento, vid. A.D.O. causa 795/38. 
ser humano necesita, además de energía (calorías) y agua, entre cuarenta y cincuenta nutrientes: de 8 a 10 aminoácidos que se obtienen de las proteínas, ácidos grasos, carbohidratos, 13 vitaminas y 18 elementos de la tabla periódica. Todos ellos deben ser aportados por los alimentos que se ingieren.

En la actualidad, el Ministerio de Sanidad considera que el número de calorías que necesita diariamente un hombre adulto (20-40 años) oscila entre las 2.700 y 3.000 , mientras que una mujer adulta necesita entre 2.075 y 2.300. Aunque se acepta que las necesidades individuales de energía varían en función del tamaño corporal y la actividad física, además de por la edad, el sexo e incluso factores genéticos. No cabe duda, teniendo en cuenta tanto las cantidades como los componentes del rancho que hemos citado en los apartados anteriores, que los presos españoles de posguerra estaban sometidos a una dieta hipocalórica.

Pero, además de baja en calorías, la alimentación de los reclusos - como la de una importante masa de españoles durante la posguerra - será también desequilibrada, o lo que es lo mismo, estarán ausentes algunos nutrientes básicos como las proteínas y, sobre todo, las vitaminas. La consecuencia será la aparición de enfermedades carenciales que, después de la tuberculosis y el tifus, serán responsables de buen número de los fallecimientos que se producen en las prisiones; aunque, si tenemos en cuenta la estrecha relación que la subalimentación guarda con muchas de las patologías que afectan a los reclusos, quizá debamos considerar que esta es, en realidad, la principal causa de mortalidad.

A lo largo de 1940, en la Prisión del Puerto de Santa María, el «síndrome carencial» es responsable de aproximadamente el $15 \%$ de los fallecimientos, y además, la anemia - cuya principal causa es la desnutrición - representa un 5\% (las insuficiencias cardíacas, a menudo causa de la muerte en síndromes anémicos, se elevan a un 12,71\%). Aunque la tuberculosis representa más de un $36 \%$ de los fallecimientos, es indudable que esta enfermedad encuentra un terreno idóneo en cuerpos ya debilitados por la escasez de alimentos ${ }^{25}$; Ramón Rubial es-

25 Daniel Gatica Cote, «Una cárcel de posguerra. La Prisión Central de El Puerto de Santa María en 1940», en Jaume Sobrequés, Carme Molinero y Margarida Sala (eds.), Los campos de concentración y el mundo penitenciario en España durante la guerra civil y el franquismo, Crítica-Museu d'Historia de Catalunya, Barcelona, 2003, p. 634 . 
timaba que «el setenta por ciento de los reclusos» de este penal padecían de avitaminosis ${ }^{26}$, la forma más común de las enfermedades carenciales. También en la Prisión Central de Burgos el 12,25\% de los fallecidos entre 1939 y 1943, lo habrían sido como consecuencia de la avitaminosis ${ }^{27}$.

En 1941 la Dirección General de Prisiones dará su autorización para que aquellos reclusos que presentan síntomas carenciales puedan recibir el racionado de enfermería, pero será tan elevado número de presos que en algunos centros de reclusión son sometidos a este tipo de dieta que las autoridades centrales acabarán entendiéndolo como un abuso por parte de los funcionarios y reclusos auxiliares. Para poner fin a esta situación, «a fin de evitar torcidas interpretaciones y terminar con el abuso donde éste se ha producido», se establece que sólo podrán recibir ración de enfermería por carencia aquellos reclusos para quienes el Médico Oficial lo haya prescrito, «limitando su concesión a los casos evidentes de plena justificación». Sobre todo, se pretende acabar con lo que parece una práctica habitual por parte de los médicos reclusos que, para garantizar una alimentación suficiente a sus compañeros, incrementan la cifra de carenciados rotando a la población reclusa de modo que todos reciban la dieta de enfermería. Se prohíbe a los directores y médicos oficiales, bajo la amenaza de sanciones administrativas y judiciales, que deleguen en los médicos reclusos el dictamen y la asignación del racionado de carenciado y en el caso de que alguno de estos dictámenes resulte corregido por la Inspección, dichos reclusos serán dados de baja en el destino perdiendo los beneficios acumulados de redención y trasladados, como castigo, a la Prisión de Las Palmas ${ }^{28}$.

Poco después y para hacer frente a los problemas médicos que ya empieza a plantear la insuficiente alimentación, la Inspección Central de Sanidad remitirá a todos los centros de reclusión una larga circular en la que, con todo detalle, se establecen los alimentos y cantidades que deben componer lo que se consideran cuatro dietas tipo, en función de la actividad

${ }^{26}$ Cit. Isaías Lafuente, Esclavos por la patria. La explotación de los presos bajo el franquismo, Temas de Hoy, Madrid, 2002, p. 246.

27 Isaac Rilova Pérez, Guerra civil y violencia política en Burgos (1936-1943), Dossoles, Burgos, 2001, p. 295.

${ }^{28}$ Archivo del Centro Penitenciario de Pereiro de Aguiar, Ourense (A.C.P.P.A.Ou), $\mathrm{Di}$ rección General de Prisiones. Circulares y otros documentos, escrito de la Dirección General de Prisiones con fecha 16 de septiembre de 1941. 
y situación de los reclusos (basal, de trabajo mínimo, de trabajo máximo y carencial), junto con las tres dietas de enfermería. Los productos, así como las cantidades, que deben incorporarse a cada una de esas dietas se recogen en el siguiente cuadro $n .^{\circ} 1$.

\section{Cuadro 1}

Dietas propuestas por la Dirección General de Prisiones (en grs.)

\begin{tabular}{|c|c|c|c|c|c|c|c|}
\hline & \multicolumn{4}{|c|}{ Dietas Tipo } & \multicolumn{3}{|c|}{ De Enfermería } \\
\hline & Basal & $\begin{array}{l}\text { Trab. } \\
\text { Mínima }\end{array}$ & $\begin{array}{l}\text { Trab. } \\
\text { Máximo }\end{array}$ & Carencial & Corriente & Láctea & $\begin{array}{l}\text { Pan y } \\
\text { fruta }\end{array}$ \\
\hline Pan & 250 & 250 & 250 & 250 & 250 & & 250 \\
\hline Patatas & 700 & 1.050 & 1.400 & 700 & 700 & & \\
\hline Lentejas & 140 & 210 & 280 & 140 & 140 & & \\
\hline Chorizo & 10 & & & & & & \\
\hline Carne & 45 & 57,5 & 90 & 90 & 100 & & \\
\hline Aceite & 25 & 37,5 & 50 & 37,5 & 50 & & \\
\hline Huesos & 10 & 15 & 20 & 10 & & & \\
\hline Verdura & 200 & 300 & 400 & 100 & 300 & & \\
\hline Zanahorias & 50 & 75 & 100 & 100 & 50 & & \\
\hline Sal & 10 & 15 & 20 & 15 & 30 & & \\
\hline Pimiento & 1 & 1,5 & 2 & & 1 & & \\
\hline Cebolla & 20 & 30 & 40 & 30 & 30 & & \\
\hline Azúcar & 10 & 15 & 20 & 20 & 20 & 50 & \\
\hline Ajos (Unid.) & 1 & 1,5 & 2 & 1 & 1 & & \\
\hline Café o malta & & 15 & 20 & 20 & 20 & & \\
\hline Leche & & & & 250 & 250 & 3 litros & 3 litros \\
\hline Fruta & & & & 150 & 150 & & 150 \\
\hline Pescado & & & & & 100 & & \\
\hline
\end{tabular}

Fuente: Elaboración propia a partir de la circular de la Dirección General de Prisiones de 1941. 
Se reconoce desde la Inspección que «la población reclusa se encuentra al borde de la carencia, y en algunos casos ya en ella», lo que, en su opinión, respondería a dos causas: «una, la falta de calorías totales o de alguno de los principios inmediatos de hidratos de carbono, grasas y proteínas en cantidad suficiente, y otra, la falta de ritmo en la proporción en que se encuentra la dieta». La llamada dieta basal (que aportaría 2.086 calorías diarias) se propone para equilibrar estas carencias pero admitiendo «que se encuentra tan próxima a la insuficiencia» ${ }^{29}$ que podría aumentarse en determinados casos, especialmente si el recluso está enfermo o realiza algún tipo de esfuerzo físico. Para facilitar el suministro se establecen equivalencias entre los alimentos que componen esta dieta, de manera que se puedan substituir unos por otros, así 25 grs. de aceite equivalen a 75 de tocino; las judías y los garbanzos se hacen equivalentes a las lentejas; el pescado puede substituir a la carne (90 grs. por los 45 de carne). Se incluyen las zanahorias dado su alto contenido en vitamina A, carencia que junto con la de proteínas se considera la más frecuente. No se incluye la fruta, fuente fundamental de vitaminas, «por la elevación en el precio» que representaría y tampoco la leche porque la adulteración a que se encuentra sometida no permite el cálculo calórico (se considera que la leche tiene un valor inferior al 50\%). Tampoco entran en el cálculo las calorías aportadas por verduras, cebollas y zanahorias considerando que aportan lo que se pierde en otros alimentos a la hora de su condimentación.

A partir del presupuesto disponible, en un centro de reclusión con una población de 1.000 internos se podrían dar diariamente 700 raciones de «dieta basal», 100 de trabajo mínimo, 100 de dieta carencial, 50 de «dieta de enfermería» y las 50 raciones restantes se repartirían entre la «dieta de trabajo máximo», «dieta láctea»y «dieta de pan y fruta» ${ }^{30}$.

Aunque desde un punto de vista teórico las dietas que se proponen cumplen con los requisitos para garantizar la subsistencia de los reclusos, si bien al borde de la carencia, los médicos que forman parte de la Inspección Central parecen vivir en un mundo aparte. Desconocen por completo la precaria situación en que se encuentran las prisiones, donde muchos de

29 Sería el resultado de un estudio realizado sobre los propios presos durante meses - aunque no se indica en qué prisión, ni sobre cuantos sujetos - y, aunque mínima en gasto y cantidades suministradas, no habría producido ningún tipo de alteración carencial.

30 Archivo Histórico Provincial de Ourense (A.H.P.Ou). Fondo Prisión Provincial, Celanova, Correspondencia, 1919/44, Circular de la Inspección Central de Sanidad de 19 de septiembre de 1941. Caja 13.041. 
los productos con los que se pide que se confeccione el rancho han desaparecido desde hace años y que apenas si tienen algo más que pan o patatas para alimentar a sus presos. Del modo en que los directores y administradores podrían conseguir los alimentos prescritos y en las cantidades necesarias no se dice ni una palabra. Pero más allá de la falta de adecuación de estas instrucciones a la realidad, lo que interesa destacar es que la Inspección Central de Sanidad es consciente de los problemas que se derivan de la insuficiente alimentación que reciben los presos y, además, reconoce que las enfermedades carenciales son algo extendido con carácter general en todas las prisiones ${ }^{31}$.

A pesar de lo anterior, la Inspección Central de Sanidad no considera la alimentación como su ámbito preferente de actuación. En una entrevista que publicaba el semanario Redención con los doctores Solves, Ortiz de Landazuri y Rey Stolle, pertenecientes a la Inspección Central, la preocupación básica que estos manifestaban era la lucha contra las enfermedades epidémicas, para cuya erradicación se habían publicado unas extensas normas de actuación que se pedía cumplir con el máximo rigor, además de solicitar la «colaboración entusiasta de la propia población reclusa». En especial se pretendía acabar con la plaga de piojos que asolaba las prisiones y que era responsable de la extensión del tifus exantemático. Un problema que consideraban en gran medida superado gracias a la instalación en las prisiones de «cámaras de cianhidrización» para despiojar las ropas y los diferentes procedimientos de desparasitación aplicados sobre la población reclusa. Para los inspectores de sanidad, a punto de culminar con éxito la campaña contra el tifus, ya no existirían grandes problemas médicos en las prisiones, «fuera de algunos casos de gripe» ${ }^{32}$. Pero, sobre la alimentación de los reclusos y sus consecuencias, con abundantes casos de «estados precarenciales» que por entonces ya empezaban a hacerse evidentes en todas las prisiones, la Inspección no tiene nada que decir, y ello a pesar de que enfermedades leves - como la gripe que citan - pueden transformarse en auténticas epidemias graves como consecuencia del estado de depauperación en que se encuentra la mayor parte de la población reclusa.

${ }^{31}$ Cuando tres años más tarde se acuerda incrementar el coste de la ración por plaza y día a tres pesetas, se insistirá en que con este presupuesto el número de calorías por recluso debe alcanzar como mínimo las 2.000 , lo que significa que con anterioridad no se llegaba a esa cantidad.

32 REDENCIÓN. Órgano... op. cit., 9 de agosto de 1941, p. 4. 
A comienzos de 1942 los efectos de la deficiente alimentación empiezan a manifestarse con toda su crudeza en las condiciones sanitarias de las prisiones, lo que llevará a que algunos médicos llamen la atención de la Dirección General de Prisiones sobre las posibles consecuencias de esta situación. En la prisión Provincial de Albacete el médico entiende que una buena parte de la población reclusa, aún sin padecer enfermedad ninguna, «manifiesta signos evidentes precarenciales», de lo que hace responsable al «insuficiente número de calorías que la ración normal del recluso posee». Este estado precarencial, además de una menor resistencia para el trabajo, lleva consigo una disminución de las defensas que los hace extremadamente vulnerables «ante probables y presumibles estados patológicos». Para este médico existe «un temor fundamentado de un aumento excesivo de la mortalidad en fechas próximas» provocado por las enfermedades que pudieran afectar a estos presos. Como medida de prevención solicitará que se incremente en 20 el número de plazas de racionado de enfermería que, añadidas a las existentes ( $8 \%$ de la población reclusa), permitirían «establecer grupos cíclicos de 20 individuos en dichas condiciones durante un determinado número de días» ${ }^{33}$.

Casi simultáneamente el médico de la prisión provincial de Orense remite un informe similar al Director del Centro en el que le advierte de la «aparición de múltiples casos de depauperación entre la población reclusa en una proporción cercana al $25 \%{ }^{34}$. Para evitar la extensión de la enfermedad y poner fin a los estados de carencia que existen, el médico cree necesario reforzar la alimentación con el suministro de vitaminas que pueden adquirirse en la Farmacia Militar. ${ }^{35}$

La Dirección de la prisión remitirá el informe a la Dirección General pero las autoridades centrales no atenderán esta solicitud y contestan

33 Escrito del Médico oficial de la prisión presentado a la Junta de Disciplina el 20 de enero de 1942. Cit. Manuel Ortíz Heras, Violencia política en la II República y el primer franquismo, Siglo XXI, Madrid, 1996, p. 317.

${ }^{34}$ Escrito con fecha 19 de febrero de 1942. A.H.P.Ou. Fondo Prisión Provincial. Estadística sobre sanidad y enseñanza, 1942, Caja 12.923.

35 Dado que el $20 \%$ del fondo de reclusos del economato - a cargo del cual deben las prisiones atender a las necesidades específicas de sanidad - se encuentra prácticamente agotado, el Director solicita de la Inspección Central de Sanidad autorización para justificar en la cuenta de Medicamentos o Sanidad el importe «de diez a quince frascos mensuales de un específico servido por la Farmacia Militar que contiene vitaminas A y D» cuyo precio es de 7,30 ptas. Escritos con fecha 19 de febrero de 1942. A.H.P.Ou. Fondo Prisión Provincial. Estadística sobre sanidad y enseñanza, 1942, Caja 12.923. 
al médico de la prisión que, aunque satisfechos por «la voz de alarma sobre la llamada dieta de enfermería», entienden que la administración de vitaminas A y D para solucionar el problema les parece «poco fundamentada». Para contar con un mayor conocimiento que les permita acordar las medidas que se deben aplicar piden al médico que envíe un informe en el que se de cuenta de la dieta ordinaria de los días 10 de cada mes desde enero de 1941, el número de carenciados y fallecidos durante esos meses, las carencias específicas y el valor de la dieta de enfermería que se suministra $^{36}$. Quizás por esta falta de confianza en su competencia profesional, el médico envía, además de las estadísticas solicitadas, un largo informe en el que expone sus propias conclusiones sobre la dieta alimenticia y el proceso carencial que afecta a los reclusos. Dicho informe presenta un cuadro realmente tétrico de la prisión Provincial de Ourense a lo largo del año 1941 y especialmente en los primeros meses de 1942 que podemos, sin dificultad, hacer extensivo al resto de las prisiones del país.

Después de una cuidadosa comparación entre la dieta basal oficial y lo que efectivamente se suministra en la prisión, afirma, sin ningún tipo de duda, que «la dieta alimenticia de los reclusos sanos, en general (...) es inferior a la que se señala como tipo o índice mínimo», de modo que habrían estado por debajo de lo normal durante todos los meses considerados, además, pone de manifiesto que en el cálculo de cantidades realizado por la Inspección Central se consideran las raciones que salen del almacén, antes de ser cocinadas, es decir, no se tiene en cuenta lo que se pierde en su elaboración y los desperdicios que en algunos alimentos, como la carne o el pescado pueden significar entre un 15 y un $20 \%$ de su peso. Baja en calorías y proteínas, la dieta carece casi por completo de vitaminas ya que las pocas que contienen los alimentos utilizados son destruidas en el proceso de cocción y a los presos no se les suministra fruta fresca ni ensaladas en crudo.

Señala el médico que una dieta escasa no produce inicialmente trastornos graves, pero cuando ésta se prolonga a lo largo de los meses «las reservas desaparecen, el organismo se nutre a expensas de sus propios tejidos y el estado morboso aparece entonces con caracteres alarmantes, acentuándose cada vez más». Las consecuencias no tardan en llegar, en forma de avitaminosis: entre noviembre de 1941 y febrero de 1942 se habrían producido 28 casos de esta dolencia, prácticamente la mitad (12) en

36 Escrito con fecha 26 de febrero de 1942. A.H.P.Ou. Fondo Prisión Provincial. Estadística sobre sanidad y enseñanza, 1942, Caja 12.923. 
el último mes. El médico daba la voz de alarma no sobre el estado carencia, que ya conocía con anterioridad y que le había llevado a disponer que todos los reclusos que presentasen síntomas de desnutrición recibiesen la ración de enfermería, su preocupación se incrementa porque esa solución ya no es suficiente y de lo que se podía considerar como «carencias generales» se estaba pasando en los últimos meses a otras más específicas y graves como el edema o la avitaminosis ${ }^{37}$.

Apunta con total claridad cuál es la raíz del problema: con un presupuesto de 2 pesetas por recluso y día es imposible atender las necesidades de alimentación de los más de 400 presos existentes. El constante incremento en el precio de los productos básicos, incluidos los sometidos a tasa por la Delegación Provincial de Abastecimientos, hace imposible su adquisición y, además, muy a menudo no es posible suministrar algunos de ellos «por falta o escasez de existencias en los almacenes de la localidad». Muchos de estos productos no pueden conseguirse tampoco en el mercado libre y los que es posible encontrar tienen un precio que los hace prohibitivos para la prisión. Por ello entiende que es necesario incrementar el importe de la ración normal, al menos en 0,50 ptas. por plaza y día o, cuando menos, incrementar en esa misma cantidad la ración de enfermería, de modo que todos los reclusos aquejados de carencia y «aquellos que no pueden recibir de sus familias ni comida ni aportaciones en metálico» puedan recibir esta dieta mejorada. El incremento que se propone en el presupuesto podría destinarse a la adquisición de frutas y hortalizas o legumbres verdes con lo que se podría mejorar el aporte de vitaminas ${ }^{38}$.

Quien realiza este informe es un particular sin relación alguna con la prisión, el doctor Celso Moreiras Neira, nombrado con carácter accidental por el juzgado. Quizá a esta independencia de las autoridades penitenciarias se deba la claridad y contundencia de sus palabras ${ }^{39}$. Para apoyar sus conclusiones elabora, entre enero y agosto de 1942, unos detallados «partes mensuales de avitaminosis» en los que recoge datos sobre los «edemas

37 Ibíd. Informe con fecha 15 de abril de 1942.

38 Informe con fecha 15 de abril de 1942. A.H.P.Ou. Fondo Prisión Provincial. Estadística sobre sanidad y enseñanza, 1942, Caja 12.923.

39 En el mes de julio, el Director del centro solicitaba a la Inspección Central de Sanidad el envío de un médico recluso ya que el existente se encontraba hospitalizado y señalaba que el médico nombrado por el Juzgado «viene a hacer la visita no diariamente (...) Y como se trata de un médico particular que no tiene relación alguna con el establecimiento no le puedo obligar a que venga todos los días». A.H.P.Ou. Fondo Prisión Provincial. Estadísticas sobre sanidad y enseñanza, 1942, Caja 12.923. Escrito con fecha 26 de junio de 1942. 
generalizados» y casos de «adelgazamiento y desnutrición», además del número de enfermos y curados, que resumimos en el siguiente cuadro.

\section{Cuadro 2}

Enfermedades carenciales en la Prisión Provincial de Ourense

\begin{tabular}{lcc}
\hline \multicolumn{3}{c}{ Enero-agosto de 1942 } \\
\hline \multicolumn{1}{c}{ Población reclusa media } & 417 & \\
\hline Adelgazamiento y desnutrición & Casos & Índice \\
Edema & 78 & $18,70 \%$ \\
En conjunto & 13 & $3,11 \%$ \\
\hline \multicolumn{1}{c}{ Meses con mayor incidencia: } & 91 & $21,81 \%$ \\
\hline Febrero & & \\
Marzo & 21 & \\
Abril & 30 \\
\hline
\end{tabular}

Fuente: elaboración propia.

Las enfermedades carenciales afectan a casi un $22 \%$ de la población reclusa media, es decir, uno de cada cinco internos de la prisión provincial padece desnutrición. El momento más crítico se alcanza en el mes de abril, cuando serán 59 los reclusos aquejados de este tipo de dolencias. A partir del mes de mayo prácticamente desaparecen los nuevos casos - en junio se presenta uno de desnutrición y en julio otro de edema- y a finales de agosto ya no quedará ningún recluso en la enfermería por esta causa ${ }^{40}$. No le faltaba razón al médico de la prisión cuando en febrero alertaba sobre el peligro que representaba la escasa alimentación de los reclusos y solicitaba complementarla con aportes vitamínicos; y hay que atribuir a su esfuerzo el haber conseguido frenar el avance de las enfermedades carencia-

${ }^{40}$ Los partes aparecen cosidos juntos formando una carpetilla, lo que parece indicar que son los únicos que se realizaron. 
les - fundamentalmente, por el procedimiento habitual de rotar a toda la población reclusa en la dieta de enfermería - ya que la Inspección Central de Sanidad no tendría en cuenta para nada el informe remitido, limitándose a agradecerle su interés sin tomar ningún tipo de medida al respecto.

Que se frene la incidencia de las enfermedades carenciales no significa que la alimentación de los presos haya mejorado de manera sustancial. A lo largo de 1943 en muy pocas ocasiones el racionado diario superará en la Prisión Provincial de Ourense las 2.000 calorías, que se suponía eran la cantidad mínima que debía aportar la dieta basal, y en el último cuatrimestre de ese año estará siempre por debajo de las 1.900. No debe extrañar, pues, que el peso medio mensual a duras penas llegue a los $65 \mathrm{~kg}$.

Conocemos las anteriores cifras sobre el peso de los reclusos porque será una norma que se establece con carácter obligatorio en todas las prisiones y se presentará en el Semanario Redención como una de las grandes novedades para mejorar la alimentación de los presos. Las estadísticas que señalan la evolución del peso medio servirían a la Dirección General para tener un conocimiento más preciso «en cuanto a las condiciones generales alimenticias del rancho», obviamente para poder publicitar su mejora. Junto a este estudio estadístico se habría encargado a médicos especialistas la realización de visitas de inspección a las prisiones y la elaboración, a partir de los datos obtenidos, de un informe sobre el valor calorimétrico del rancho y su aporte en vitaminas y proteínas.

Aún antes de conocer el resultado de estos análisis, el Subdirector de Prisiones no duda en afirmar que «en su confección y reparto [del rancho] han de introducirse modificaciones esenciales que subsanen defectos observados», entre otros, «la casi total ausencia» de proteínas de origen animal y de vitaminas, es decir, la falta de carne y verduras, aunque hace responsable de estos defectos a las dificultades de abastecimiento y «a la falta de dirección médica en la proporción en que son empleadas las distintas materias alimenticias». Convenientemente olvida que en el Reglamento de Prisiones aparecen pormenorizadamente detallados tanto los productos como las cantidades y que a través de la Circular de 19 de septiembre de 1941 se habían establecido tres tipos de dietas, así como los alimentos que debían formar parte de cada una de ellas; también olvida los informes enviados por diferentes médicos de prisiones en los años anteriores que llamaban la atención sobre lo precario del racionado y proponían soluciones. Lo más sorprendente de las reflexiones del Subdirector es la única solución que propone. Una de las tareas que se encomienda a los médicos-inspectores es que recaben información sobre el tamaño que tienen los cazos empleados para re- 
partir el rancho, con la finalidad de establecer «un tipo único para fijar la cantidad de cada ración», cabe pensar que con esta medida se solucionaría aquél problema de ausencia de nutrientes ${ }^{41}$.

Estas inspecciones no llegarán a todas las prisiones y la única función que tendrán asignada los inspectores médicos será permitir la realización de una campaña propagandística a través del semanario Redención. Los informes remitidos a la Dirección General, en caso de haber existido, no se tradujeron en la adopción de medidas prácticas y efectivas, ni siquiera en la uniformización de los cazos. Según se desprende de lo consignado en las actas diarias del racionado de reclusos sanos y enfermos de la prisión provincial de Ourense ${ }^{42}$, a lo largo de 1944, salvo excepciones, el número de calorías que aporta el rancho estará siempre por debajo de 1.900 - en ocasiones incluso con valores próximos a las 1.500 - hasta el mes de junio, incrementándose a partir de entonces para situarse por encima de las 2.000 aunque en muy pocos días se superan las 2.300 y serán todavía más escasos aquellos en que se alcanzan las 2.500. Probablemente, esta elevación en el número de calorías que aporta el rancho guarda relación con la circular que sobre la alimentación se había remitido a finales de julio a todas las prisiones y en la que establecía la obligatoriedad de que «el racionado de la población reclusa [alcance] desde esta fecha, en todas las prisiones, un mínimo de dos mil calorías», si bien, y a modo de compensación, se señalaba que el coeficiente máximo de enfermos no podría exceder del diez por ciento de la población reclusa de cada establecimiento ${ }^{43}$.

\section{Conclusiones}

Las deficiencias en la alimentación de los reclusos en la inmediata posguerra constituyen un problema estructural del sistema penitenciario derivado del ingente número de reclusos existente. Pero comienza con anterioridad al final de la contienda civil; a lo largo de los tres años de

${ }^{41}$ REDENCIÓN. Órgano... op. cit., 4 de septiembre de 1943, p. 1. En el número de 11 de septiembre se incluía un comentario sobre estas inspecciones destacando que las efectuadas en las prisiones madrileñas de Porlier y Yeserías habían dado como resultado sendos «informes elogiosos para los ranchos inspeccionados».

42 A.H.P.Ou. Fondo Prisión Provincial. Libro de Actas de extracción del racionado de reclusos sanos y enfermos, Libro 10.026 .

${ }^{43}$ REDENCIÓN. Órgano... op.cit., 29 de julio de 1944, p. 1. 
guerra, en las prisiones situadas en la retaguardia franquista, se asiste a un progresivo deterioro de la alimentación a medida que van desapareciendo del mercado aquellos productos que debían incluirse en el racionado diario.

En los primeros años cuarenta, los «años del hambre» para la población en general, la situación en las prisiones se vuelve dramática. La intervención de aquellos organismos creados para gestionar la autarquía, de manera especial la Comisaría General de Abastecimientos, tendrá como consecuencia que los responsables de los centros de reclusión se encuentren con enormes dificultades para conseguir los productos necesarios para la alimentación de los reclusos. A ello hay que sumar la escasez de buena parte de esos productos y el elevado precio que alcanzan los demás, que los hacen inaccesibles al magro presupuesto disponible por recluso y día para alimentación. Además, la existencia de un amplio mercado negro se convierte en una irresistible tentación para muchos funcionarios de prisiones que, sistemáticamente, desviarán hacia él buena parte de los alimentos que entran en las prisiones.

Como no podía ser de otro modo, el hambre ocupará un lugar destacado en la memoria de los presos. Sus relatos nos transmiten una situación idéntica en prácticamente todos los centros de reclusión, en los que, en el mejor de los casos, la dieta se reduce a pan y patatas. Las consecuencias no tardarán en hacerse sentir: progresiva depauperación y aparición de estados carenciales que, en algunos casos, llevarán a la muerte por inanición y en muchos otros contribuirán a hacer más virulentas otras enfermedades debido a la situación de extrema debilidad en que se encuentran la mayor parte de los presos.

Los responsables de las prisiones llamarán la atención de las máximas autoridades del sistema penitenciario - y de las más próximas autoridades civiles provinciales - sobre las dificultades insuperables que encuentran para acceder a los productos necesarios para garantizar la alimentación de los presos. Inicialmente apoyarán sus solicitudes agitando el fantasma de posibles alteraciones del orden interno que, fácilmente, podrían traspasar los muros de las prisiones; con posterioridad se centrarán en los cada vez más evidentes problemas sanitarios que se derivan de esta situación y sobre los que llamaban la atención los médicos de las distintas prisiones.

En este trabajo nos hemos centrado en el informe elaborado por el médico de la Prisión Provincial de Ourense y hemos citado otro en el mismo sentido del médico de la Prisión de Albacete, pero probablemente se elaboraron muchos otros de similar contenido. En ellos se llama la 
atención sobre la falta de calorías y el desequilibrio de la dieta, de la que están completamente ausentes las proteínas y las vitaminas. También sobre sus consecuencias: las enfermedades carenciales se extienden por las prisiones en los primeros años de la década de los cuarenta, solo con la disminución en el número de reclusos a partir de 1944 parece que se empieza a poner fin a esta situación.

La única solución que encuentran los médicos de las prisiones consiste en someter a los reclusos que presentan síntomas de desnutrición al llamado «racionado de enfermería», pero serán tantos que en muchas prisiones se establece una rotación para que toda la población reclusa reciba este racionado de mayor aporte alimenticio. Por su parte, la Inspección Central de Sanidad, dependiente de la Dirección General de Prisiones, responsable de solventar este grave problema, no se dará por enterada a pesar de los informes que recibe de Médicos Oficiales de prisiones. Acabará por establecer unas detalladas dietas, reconociendo que la denominada «dieta tipo», la que recibirían la mayor parte de los presos, se encontraba al borde de la carencia y debía ser complementada de alguna manera. Pero no parecen conocer la imposibilidad de acceder a muchos de los alimentos que citan, incluyendo aquellos que proponen como sustitutos de otros.

El momento de mayor incidencia de este tipo de enfermedades parece ser el invierno de 1941-42, después de que los reclusos hayan pasado varios meses sometidos a una dieta insuficiente. El informe que remite el médico de la prisión ourensana a la Inspección Central de Sanidad es demoledor. Demuestra que la dieta real en esta prisión es muy inferior a la dieta tipo establecida, que además de baja en calorías y proteínas carece por completo de vitaminas y apunta la razón fundamental: la insuficiencia del presupuesto de 2 pesetas por recluso y día para alimentación. A pesar de ello, los responsables del sistema penitenciario únicamente propondrán soluciones que tienen un carácter meramente propagandístico. Así, se establecerá la norma de pesar a los reclusos y las cifras medias se publicarán - convenientemente maquilladas - en el Semanario Redención, se ponen en marcha visitas de inspección - que no parecen haber llegado a todas las prisiones - para estudiar las características calorimétricas del rancho y elaborar un informe que lleve a su necesaria mejora, pero sin adoptar ninguna medida realmente efectiva. Como se ha señalado, habrá que esperar a la segunda mitad de 1944 para que la cantidad de calorías que aporta el rancho en la prisión ourensana empiece a estar por encima de las 2.000 que se establecieran como cifra mínima tres años antes. 
Resulta imposible acercarse a las cifras de fallecidos como consecuencia del hambre en el interior de las prisiones de posguerra, como también es imposible conocer el número de muertos consecuencia de otras enfermedades. Se suponen unas cifras muy elevadas y se ha convertido en un lugar común señalar que el progresivo vaciado de las prisiones en la primera mitad de los años cuarenta será una consecuencia de los fallecimientos ocurridos por las pésimas condiciones de vida en su interior, el hambre y la enfermedad, a las que habría que sumar las ejecuciones. Sin embargo, pensamos que esta afirmación debe ser, cuando menos, matizada. Si la cifra de ejecuciones que mayor aceptación tiene se sitúa en torno a las 50.000 , el número de muertos por hambre, enfermedad o «accidentes» es, a día de hoy, imposible de cuantificar.

En un análisis que no pretende ser exhaustivo, hemos recopilado datos procedentes de investigaciones realizadas en 24 provincias, muchas de ellas sólo estudiadas parcialmente ${ }^{44}$, que arrojan un total de fallecidos que ronda los 7.600 durante la década de los cuarenta, aunque con mayor incidencia en su primera mitad. Una proyección a partir de estos datos parcia-

44 En muchos casos se trata de una sola localidad, de una única prisión o son datos referidos a un periodo de tiempo de algunos meses o un par de años. En otros se hace referencia a toda la década de los cuarenta, o se incluyen cifras correspondientes a los años de la guerra civil. Finalmente, es muy habitual encontrar estimaciones y no cifras contrastadas. Gatica Cote, «Una cárcel de posguerra. La Prisión Central de El Puerto de Santa María en 1940», en Jaume Sobrequés; Carme Molinero y Margarida Sala (Eds.), Los campos de concentración y el mundo penitenciario en España durante la Guerra Civil y el Franquismo. Barcelona, Ed. Crítica, 2003, pp. 616-635. Gabriel Jackson , La República española y la Guerra Civil 1931-1939, Ed. Orbis, Barcelona, 1985.Francisco Moreno Gómez, Córdoba en la posguerra, Francisco Baena, Córdoba, 1987. Francisco Moreno Gómez, «La represión en la posguerra», en Santos Juliá (coord.), Víctimas de la guerra. Antonio Martínez Ovejero, «La represión franquista en la Región de Murcia (1936-1948) », en I Congreso de Víctimas del Franquismo, Rivas-Vaciamadrid, Abril de 2012, disponible en www.congresovictimasfranquismo.org/comunicaciones. Chaves Placios, J., «Franquismo: prisiones y prisioneros», en Pasado y memoria: Revista de Historia Contemporánea, 2005, vol. 4., p. 43. Vicent Gabarda Cebellán, Els afusellaments al País Valencià (1938-1956), Alfóns el Magnanin, Valencia, 1993. Isaac Rilova Pérez, Guerra civil y violencia política en Burgos (1936-1943), Dossoles, Burgos, 2001. 1934 nombres. Monumento a la memoria de las víctimas de la represión franquista https://www.gijon.es/multimedia_objects/ download?object_type=document\&object_id=84295. Javier Martin Bastos, «Posguerra en extremadura. Reflexiones en torno al estudio de las víctimas del terror franquista», en $M e$ moria antifranquista del Baix Llobregat, El Genocidio Franquista en Extremadura, any 8, 2012. Jesús Gutiérrez Flores, Guerra Civil en Cantabria y pueblos de Castilla, LibrosEnRed, Buenos Aires, 2006. José M. ${ }^{a}$ Ruiz Alonso, La Guerra Civil en la Provincia de Toledo. Utopía, Conflicto y Poder en el Sur del Tajo (1936-39), Almud, Ciudad Real, 2004. 
les que situase la cifra total alrededor de los 20.000 fallecidos durante la inmediata posguerra quizá no estuviera desencaminada ${ }^{45}$. Esto haría una cifra que rondaría los 70.000 reclusos que mueren en prisión por todos los conceptos. Una cifra considerable, que representa una cuarta parte del número total de los existentes en enero de 1940, el momento de mayor hacinamiento.

Pero aún cabe hacer algunas matizaciones, así, por ejemplo, en esa cifra se incluyen también los presos comunes que fallecen en prisión, que quizá supongan una parte importante del volumen total. Hay que tener en cuenta que constituyen el grupo más vulnerable por cuanto no tienen cabida en las redes de solidaridad que los políticos crean en el interior de las cárceles y, por su extracción social, generalmente no cuentan con ningún tipo de apoyo en el exterior. Si este grupo de presos contribuye a reducir la cifra de los políticos que fallecen en prisión, sin embargo, ésta habría de incrementarse con aquellos reclusos que abandonan la cárcel en libertad condicional y fallecen en el exterior a los pocos días, semanas o meses como consecuencia de enfermedades contraídas o por el estado de debilitamiento general propiciado por la dieta de hambre que se han visto obligados a seguir. Se trata de un número de fallecidos muy difícilmente cuantificable, pero que sabemos que existe, como lo sabían las propias autoridades penitenciarias. De hecho, se acordará la puesta en libertad de aquellos reclusos ya desahuciados para que su fallecimiento no modifique las estadísticas y, sobre todo, no empañe la imagen propagandística que se lleva a cabo en torno a las prisiones y el trato que reciben los presos.

45 Un acercamiento más profundo al conocimiento de estas cifras pasaría por el análisis de la documentación generada por las prisiones, allí donde se ha conservado. Los registros civiles de aquellas localidades donde se encontraban situadas las prisiones constituyen también una fuente esencial y, de hecho, la hemos empleado para el análisis las prisiones situadas en la provincia de Ourense; sin embargo, ampliar dicho análisis a las más de cien prisiones existentes durante la posguerra (en 1942 eran 45 prisiones centrales y 50 provinciales, a las que habría que sumar habilitadas, de partido, destacamentos penitenciarios, etc.) supera con creces el objetivo que nos hemos marcado en este trabajo. 